\title{
Spigelian Hernia: A Rare Variety of Ventral Hernia
}

\author{
Shahbaz Khan Panhwer*, Erum Kazim and Saeed Quraishy
}

Department of General Surgery Unit-IV Civil Hospital Karachi, Pakistan.

\begin{abstract}
Spigelian hernia is rare and generally difficult to diagnose because of its location and vague non-specific symptoms. A Spigelian hernia occurs through the Spigelian fascia, which is composed of the aponeurotic layer between rectus muscle medially and semilunar line laterally. Nearly all Spigelian hernias occur at or below the arcuate line. The absence of posterior rectus fascia may contribute to an inherent weakness in this area. These are often interparietal, with the hernia sac dissecting posterior to the external oblique aponeurosis. Patient often present with localized pain in the area without a bulge because the hernia lies beneath the intact external oblique aponeurosis and they are easily overlooked by obesity. Ultrasound or CT scan of the abdomen can be useful to establish the diagnosis. Spigelian hernias should always be surgically repaired in view of the high frequency of incarceration.
\end{abstract}

We report a 40 year old lady who presented to us with complaint of pain in her right Epigastric \& lumbar region along with vague swelling on standing. Diagnosis of Spigelian hernia was made on the basis of ultrasound \& CT scan findings \& it was confirmed on exploration. The hernia was reduced \& licheneistein mesh repair was performed, her recovery was uneventful.

doi.org/10.21089/njhs.21.0039

\section{INTRODUCTION}

A Spigelian hernia, also known as spontaneous lateral ventral hernia, interparietal, interstitial, intermuscular, or intramural hernia is a hernia through the Spigelian fascia, which is the aponeurotic layer between the lateral edge of the rectus abdominis muscle medially and the semilunar line laterally (Fig. 1). It is named after the Belgian anatomist Adriaan van den Spieghel [1]. A Spigelian hernia is generally an interparietal hernia, meaning that the preperitoneal fat and/or the hernia sac penetrate the transversus abdominis and internal oblique muscles but remain behind the external oblique aponeurosis (Fig. 2). Although Spigelian hernias can occur at any point along the spigelian fascia, they almost always develop at or below the arcuate line, probably because of the absence of posterior rectus sheath at that level. In addition, the fibers of the spigelian aponeurosis run in a parallel fashion below the umbilicus instead of crossing one another at right angles, becoming vulnerable to separation by preperitoneal fat. In fact, $90 \%$ of Spigelian hernias are found within the Spigelian hernia belt of Spangen [2], which is a 6$\mathrm{cm}$ transverse strip above the line joining both anterior superior iliac spines, and where the spigelian fascia is wider and weaker (see Fig. 1). In most cases, the hernia defect is small less than $2 \mathrm{~cm}$ with well-defined and firm margins. Spigelian hernias are normally acquired conditions, although congeni

*Address correspondence to this author at the Department of General Surgery Unit-IV Civil Hospital Karachi, Pakistan.

E-mail: shahbazpanhwer149@gmail.com tal cases have been reported in children. Predisposing factors include factors increasing intra-abdominal pressure. We report this rare variety of hernia found in one of our patients with review of literature to discuss the diagnosis \& management, as such kind of hernias are clinically elusive with fatal outcomes if ignored.

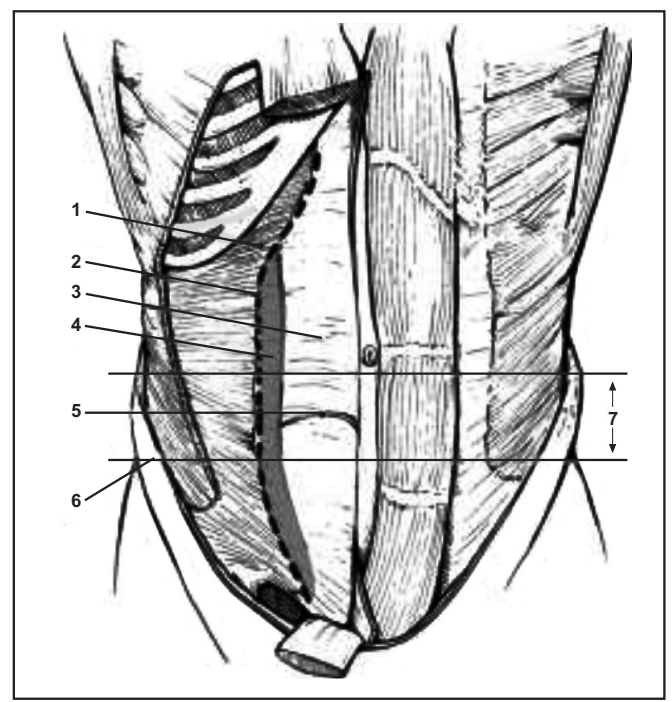

Fig. (1). View of the anterior abdominal wall with the external oblique, internal oblique, and rectus abdominus muscles peeled away on the left.

(1) Transverses muscle, (2) Semilunar line, (3) Posterior rectus sheath, (4) Spigelian aponeurosis, (5) Arcuate line, (6) Anterior superior iliac spine, (7) Spigelian hernia belt.

www.njhsciences.com 


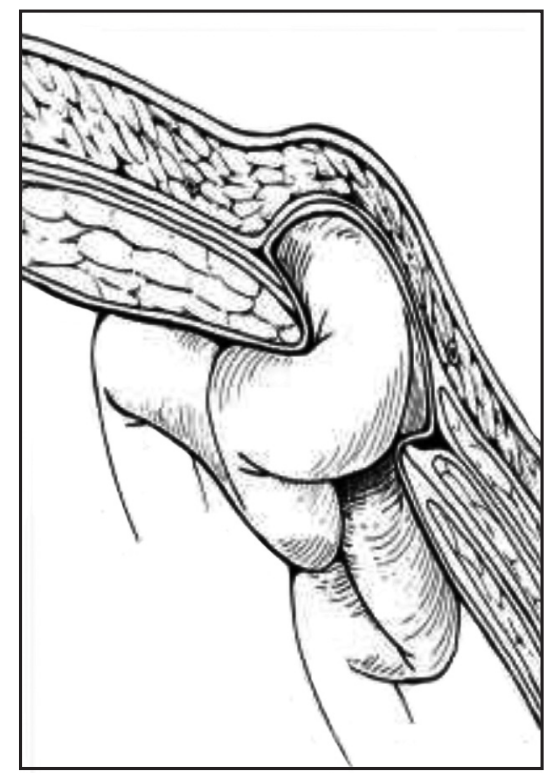

Fig. (2). Cross-sectional view of a Spiegelian hernia showing the relationship of the hernia sac to the anterior abdominal wall muscles and fascias.

\section{CASE REPORT}

A 40 year old lady with no known co-morbid presented in the surgical OPD with complain of pain in her epigastrium \& right lumbar region along with vague swelling in her right lumbar region on standing for 6 months. Initially she had complained of vague discomfort but since 3 months she noticed a vague swelling in her right lumbar region. She denied any disturbance in her bowel habits. On examination there was about $4 \times 4 \mathrm{~cm}$ vague lump on lateral border of right rectus muscle with no prominent cough impulse, swelling reduced on lying down position.

Clinical impression of Spigelian hernia was made on the basis of history \& examination findings. Her routine investigations were within normal range. X-ray abdomen didn't show any air fluid level or distended gut loops. Her Ultrasound abdomen was performed which showed herniation of Bowel loops in right rectus sheath.

CT scan of abdomen was performed which revealed herniation of small bowel loops in right rectus sheath with no signs of obstruction or strangulation of bowel loops confirming the diagnosis of Spigelian hernia.

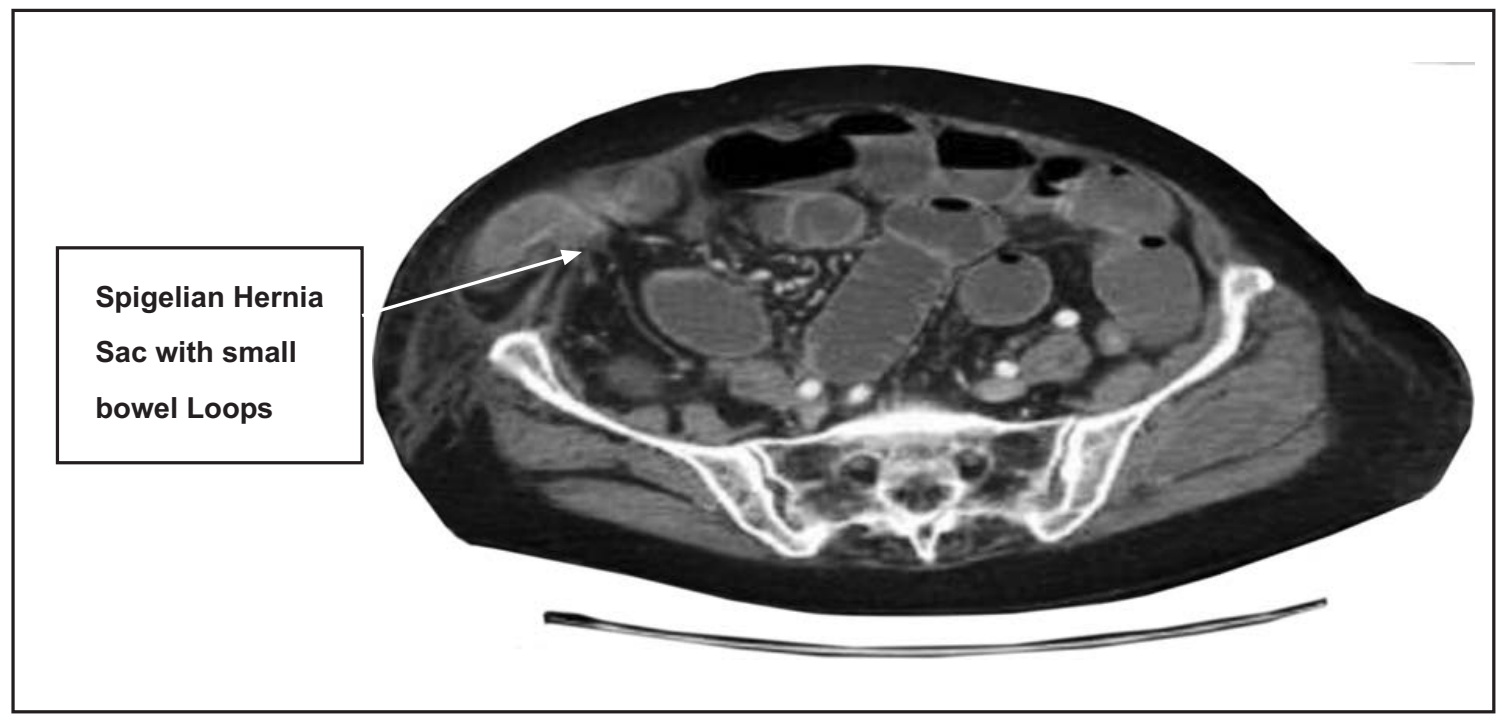

Fig. (3). CT scan abdomen region.

After adequate preparation she was explored under general anesthesia \& after all aseptic measures, $5-6 \mathrm{~cm}$ transverse incision was given extending from lateral border of right rectus, skin \& subcutaneous tissues were divided, sac identified coming in between rectus muscle, sac was freed from surrounding tissues using blunt dissection, sac was reduced, there was defect of about $4 \mathrm{~cm}$ which was repaired with prolene 2/0 suture, mesh was applied using prolene interrupted sutures via onlay technique. Reduvac drain was placed \& abdomen closed in layers, skin closed with prolene subcutaneous suture. Postoperatively patient had an uneventful recovery, she remained well when seen in surgical outpatient department after 2 weeks, her consecutive follow-ups in OPD were unremarkable.

\section{DISCUSSION}

Spigelian hernias represent $0.12 \%$ to $2.4 \%$ of all abdominal wall hernias, although their incidence appears to be increasing, given the improved detection on cross-sectional imaging. They present most commonly in the fifth and sixth dec- 
ades of life, but can be seen at any age. They have a slightly higher preponderance in women (female to male ratio, 1.4: 1) [2]. The diagnosis of a Spigelian hernia is elusive and requires a high index of suspicion, given its rarity, the vague associated abdominal complaints, and the frequent lack of consistent physical findings.

The clinical presentation varies, depending on the size, the type, and the contents of the hernia. In patients with a reducible hernia, the most common symptoms are pain and a lateral bulge or mass when standing. In its earliest form it is simply a protrusion of preperitoneal fat through the spigelian aponeurosis. The hernia can also be part of extraperitoneal organ, but a peritoneal sac is found in most cases. If the peritoneal sac has content, it is usually the greater omentum, small intestine or part of colon. Spigelian hernias are rarely known to contain inflamed appendix, crohn's appendicitis, even an incarcerated Meckel's diverticulum. Bilateral spigelian hernias are rare. Ritcher type of spigelian hernia has also been reported. Such type of hernias have also been reported following laparoscopic procedure, though a preexisting fascial weakness, that became manifested as a result of pneumo-peritoneum. The symptoms that cause a patient to consult a physician are usually abdominal pain, a mass in anterior abdominal wall or signs of incarceration with or without signs of intestinal obstruction, given the small size of the hernia orifice; incarceration at the time of operation is seen in $17 \%$ to $24 \%$ of reported hernias[2,3]. Physical examination should be carried out while the patient alternately tenses and relaxes the abdominal muscles. When the abdominal muscles are tensed all patients with spigelian hernia have a tender spot over the hernial orifice in the spigelian aponeurosis. On palpation the hernia is pressed against the ring which is firm when intraabdominal pressure is raised. This finding is not pathognomic of spigelian hernia but offers a useful method for screening. Physical examination alone fails to detect any findings in $36 \%$ of patients [3] and can be falsely positive in up to $50 \%$ of cases [4]. Given that most hernias are small and covered by a usually intact external oblique aponeurosis, it is difficult to palpate a hernia or a hernia defect. Persistent point tenderness in the spigelian aponeurosis with a tensed abdominal wall is often the only sign upon physical examination that suggests the diagnosis [1]. The appearance of the lesion is comparable with others in and around the abdominal wall, including rectus sheath haematoma, seroma, parietal abscess, lipoma, peritoneal tumor implants and pseudocyst at the end of ventriculoperitoneal shunt. Imaging is recommended before surgical exploration, especially when the diagnosis is in doubt. Ultrasonography is accurate in displaying defects in the spigelian fascia [5,6]; it is easy to perform and not expensive, but is operator dependent. CT scan also allows the diagnosis of Spigelian hernia and gives more detailed information on the contents of the sac than does ultrasonography $[6,7]$. The true sensitivity and specificity of these diagnostic techniques is, however, unknown; in one study, false-negative CT occurred in $32 \%(6 / 19)$ of patients with obvious findings of a Spigelian hernia at the time of operation [8]. Modern helical CT is probably more accurate, and it is currently uncommon not to be able to confirm the diagnosis before surgical exploration. Only occasionally is diagnostic laparoscopy required to establish the diagnosis in patients with unclear acute or chronic pain.

Spigelian hernias should always be surgically repaired in view of the high frequency of incarceration. Various techniques have been described and are currently performed. Repair of this hernia has traditionally been accomplished with a targeted transverse incision and primary tissue repair $[2,3,9]$. In one institutional review of 70 primary repairs with a mean follow-up of 8 years, the recurrence rate was $4.3 \%$, with recurrences occurring at an average of 3 years postoperatively [3]. However, in another report of 21 primary repairs, the recurrence rate was high at $14.3 \%$ [10].The addition of mesh to the open repair of Spigelian hernias has led to improved outcomes [10-14]. The various reported techniques involving mesh include intra and preperitoneal sublay mesh placement [10-12], obliteration of the ring by a preformed polypropelene mesh umbrella type plug [13], or a combination of preperitoneal underlay mesh connected to an overlay mesh lying over the internal oblique muscle [12]. None of the published series using mesh have reported any recurrences with variable follow-up periods.

Laparoscopic repair was first reported in 1992 [15]. Intraperitoneal, transabdominal preperitoneal, and totally extraperitoneal laparoscopic techniques with underlay mesh placement have been described [15].

In a prospective randomized trial; comparing 11 open and 11 laparoscopic (8 intraperitoneal, 3 totally extraperitoneal) Spigelian hernia repairs, laparoscopy was shown to have a significantly lower morbidity and shorter hospital length of stay; no recurrences were noted in either group, with mean follow-up of 3.4 years. The best results are offered by the extra peritoneal laparoscopic approach.

\section{CONFLICT OF INTEREST}

Declared none.

\section{ACKNOWLEDGEMENT}

Prof. Sajida Qureshi, Dr. Siraj Haider, Dr Jawad Azeem Khan and all team of Surgical Unit IV Civil hospital Karachi.

\section{REFERENCES}

[1] Spieghel A. Opera quae extore omnia. Amsterdam: John Bloew; 1645.

[2] Spangen L. Spigelian hernia. World J. Surg., 1989; 13(5): 573-80. 
[3] Larson DW, Farley DR. Spigelian hernias: repair and outcome for 81 patients. World J. Surg., 2002; 26(10): 1277-81.

[4] Stirnemann H. [The Spigelian hernia: missed? rare? puzzling diagnosis?]. Der Chirurg; Zeitschrift fur alle Gebiete der operativen Medizen. 1982; 53(5): 314-7.

[5] Nelson RL, Renigers SA, Nyhus LM, Sigel B, Spigos DG. Ultrasonography of the abdominal wall in the diagnosis of spigelian hernia. The American Surgeon. 1980; 46(7): 373.

[6] Balthazar EJ, Subramanyam BR, Megibow A. Spigelian hernia: CT and ultrasonography diagnosis. Gastrointest. Radiol. 1984; 9(1): 81-4.

[7] Luedke M, Scholz FJ, Larsen CR. Computed tomographic evaluation of spigelian hernia. Comput. Med. Imag. Grap., 1988; 12(2): $123-9$

[8] DeysineM.Epigastric hernias. In: BendavidR, Abrahamson J, ArreguiME, et al., editors. Abdominal wall hernias: principles and management. $1^{\text {st }}$ edition. New York: Springer-Verlag; 2001. 685-7.

[9] Artioukh DY, Walker SJ. Spigelian herniae: presentation, diagnosis and treatment. J. Royal Coll. Surg. Edinb., 1996; 41(4): 241-3.
[10] Mouton WG, Otten KT, Weiss D, Naef M, Wagner HE. Preperitoneal mesh repair in Spigelian hernia. Int. Surg., 2005; 91(5): 262-4.

[11] Montes IS, Deysine M. Spigelian and other uncommon hernia repairs. Surg. Clin. North Am., 2003; 83(5): 1235-53.

[12] Moreno-EgeaA, Carrasco L, Girela E, et al. Open vs laparoscopic repair of spigelian hernia: a prospective randomized trial. Arch. Surg., 2002; 137(11): 1266-8.

[13] Carter JE, Mizes C. Laparoscopic diagnosis and repair of Spigelian hernia: report of a case and technique. Am. J. Obstet. Gynecol. 1992; 167: 77-8.

[14] Felix EL, Michas C. Laparoscopic repair of spigelian hernias. Surg Laparosc Endosc 1994; 4(4): 308-10.

[15] Palanivelu C, Vijaykumar M, Jani KV, et al. Laparoscopic transabdominal preperitoneal repair of spigelian hernia. JSLS 2006; 10(2): $193-8$

(C) 2017 National journal of health sciences.

This is an open-access article. 